\title{
Application of an improved intracardiac fibreoptic system
}

\author{
L. JEROME KROVETZ, JOEL I. BRENNER, MICHAEL POLANYI, AND \\ DAVID OSTROWSKI
}

From the Department of Pediatrics, University of Virginia Medical School, Charlottesville, Virginia, and the Clinical Instruments Corporation, Dudley, Massachusetts, USA

SUMMARY An improved fibreoptic in vivo haemoreflection system has been used in over 200 patients. Continuous recording of oxygen saturation while moving the catheter permits measurement 9 of simultaneous pressure and oxygen saturation at almost an unlimited number of sites through the right heart. The oxygen saturation can be continuously monitored and the response is sufficiently fast to permit investigation of changes in oxygen saturation during portions of the cardiac cycle.

Dye dilution curves have been recorded from over 200 patients. The only blood withdrawn for the dye dilution curve was the $3 \mathrm{ml}$ needed for checking the calibration of the instrument. We have found that the calibration is extremely stable. In some instances where it has been deemed impractical to obtain blood for calibration, the calibration factor for each catheter may be used. In any case, the $\infty$ calibration check is performed at the end of the study and does not present problems of sterility. The calibration factor may yield a correction factor which then applies uniformly to all the cardiac output values obtained during the study.

The development of the fibreoptic technique, which allows continuous measurement of oxygen saturation without withdrawal of blood samples, was a major advance in cardiac catheterisation techniques. The same catheter and instrument may be used to record dye dilution curves for determination of cardiac output or an estimation of the degree of shunts. Practical instruments for such uses were described as early as 1964 by Ensin et al., and in 1965 by Gamble et al., Hugenholtz et al., and Frommer et al.

Since the studies noted above, the instruments have been improved by three major changes. (a) Solid state construction, in particular use of lightemitting diodes instead of incandescent lamps and colour filters, has greatly increased the stability and reproducibility of the reading and, at the same time, reduced the bulk and cost of the device. (b) Substitution of the glass optical fibres with plastic ones, which are practically unbreakable, has greatly increased the life and reduced the cost of the catheters. (c) Factory calibration of catheters for both $\mathrm{O}_{2}$ saturation and dye (indocyanine green) concentration.

\section{Subjects and methods}

Studies were carried on in the cardiopulmonary laboratory, the Children's Medical and Surgical Center of the Johns Hopkins Hospital, and in the Cardiovascular Laboratory at the University of Virginia Hospital. In over 200 children undergoing cardiac catheterisation for a variety of cardiac 3 lesions, studies were carried out with the fibreoptic haemoreflection technique ${ }^{1}$ in addition to conventional procedures necessary to establish a $\circ$ diagnosis. In 30 patients, oxygen saturations were determined by means of the fibreoptic technique. In all of these, intracardiac oxygen saturation was measured in vivo simultaneously with a sampling $N$ of blood through a lumen in the fibreoptic catheter. N These samples were analysed by a spectrophoto- N metric method. A diagram of the instrument $\omega$ employed is shown in Fig. 1; the response time can be set in discrete steps between $0 \cdot 1$ and 2 s. Its $\frac{\mathscr{C}}{\overparen{D}}$

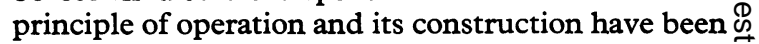
described previously by Polanyi $(1974,1975)$, and only a brief summary will be given here.

The fibreoptics catheter (Fig. 2) contains

IInstrument loaned by American Optical Co, Boston, MA. 


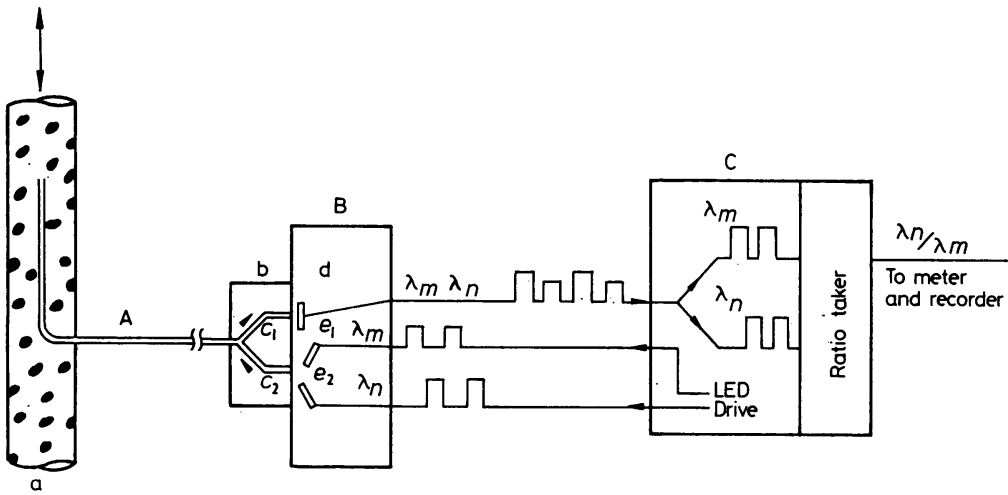

Fig. 1 Block diagram of in vivo oximeter. A-catheter; $B$ optical box; $C$-electronic package; $a$-blood vessel; $b$-terminal block of catheter; $c_{1}$ and $c_{2}-$ afferent and efferent fibres; $d-$ photocell; $e_{1}$ and $e_{2}$-light emitting diodes ( $L E D$ 's). (Published through the courtesy of Butterworths, London.)

number of afferent and efferent optical fibres ( 1 or 2 of each; $0.25 \mathrm{~mm}$ in diameter). The afferent fibres are illuminated in rapid sequence (about 300 cycles per second) by light of two colours from pulsed light emitting diodes. A portion of the light back scattered by the blood cells in the proximity of the tip of the catheter is picked up by the efferent fibres and detected. The ratio of the back scattered light intensities after appropriate scaling is a direct measure of the $\mathrm{O}_{2}$ saturation, or of $\mathrm{dye}^{2}$ concentration. The colours of lights (wave length) used in these determinations are centred around $660 \mathrm{~nm}$ and $805 \mathrm{~nm}$ for $\mathrm{O}_{2}$ saturation, and around $805 \mathrm{~nm}$ and $930 \mathrm{~nm}$ for dye concentration. The ratios of the back scattered intensities are taken as $805 \mathrm{~nm} / 660 \mathrm{~nm}\left(\mathrm{O}_{2}\right.$ saturation $)$ and $930 \mathrm{~nm} / 805 \mathrm{~nm}$ (dye concentration).

The catheters used in this study ranged in size

${ }^{2}$ Cardio Green.

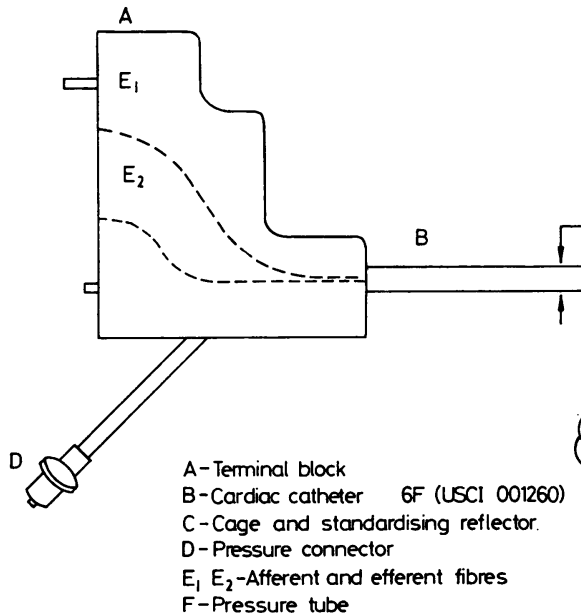

from $5 \mathrm{~F}$ to $7 \mathrm{~F}$. The $6 \mathrm{~F}$ and $7 \mathrm{~F}$ catheters are equipped with a small lumen (Fig. 2) for sampling and pressure measurements. The catheters are constructed from standard Lehman catheters (Ensin et al., 1964; Gamble et al., 1965).

A smaller catheter $8 \mathrm{~cm}$ long and of such size as to pass through a No. 18 gauge Teflon needle, ${ }^{3}$ has also been found useful; these catheters are $2 \mathrm{~mm}$ longer than the Teflon sheath. They are particularly useful for dye-dilution studies for which only an interarterial needle is used.

\section{CALIBRATION}

The catheters are factory calibrated for both dye concentration and oxygen saturation. For $\mathrm{O}_{2}$ saturation two numbers are supplied: 'gain' and 'standardisation'. After the 'gain' is set, the 'stan-

'B-D 'Longdwell' catheter needles by Becton and Dickinson, Rutherford, New Jersey.

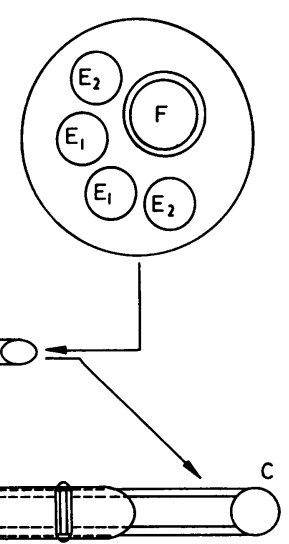

Fig. 2 Schematic drawing of fibreoptics catheter. (Published through the courtesy of Butterworths, London.) 


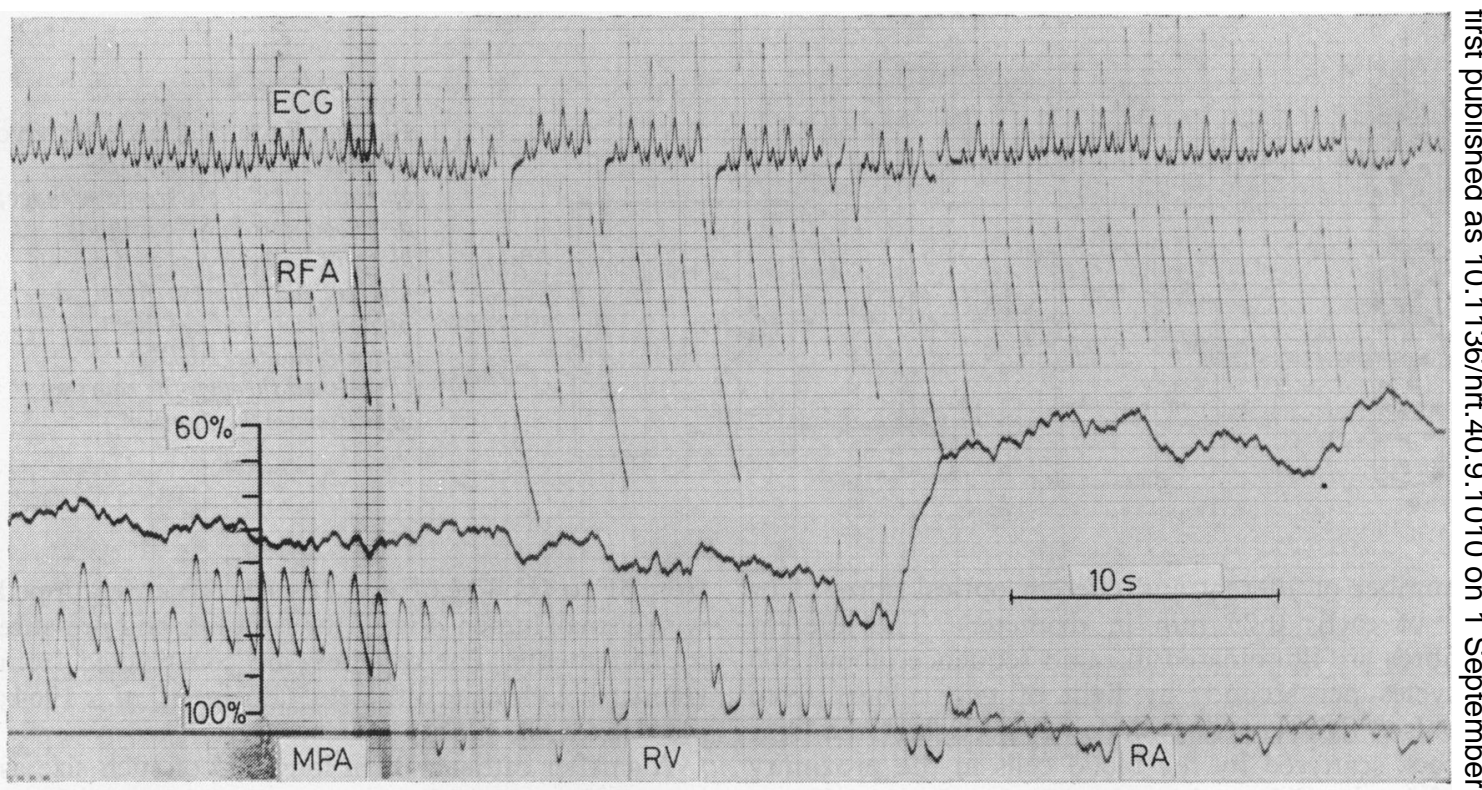

Fig. 3 Tracings recorded on withdrawal from right pulmonary artery to right atrium in a patient with a ventricular septal defect.

dardisation' is adjusted with the catheter tip immersed in sterile normal saline. The catheter is then calibrated and ready for use. For dye concentration only the 'gain' factor is needed. Gain may be set at any time during the procedure with the catheter tip in situ, before injection of the dye. For cardiac output, the amount of the dye injected is set by discrete steps with a control on the cardiac output computer. The linear range of the system is 0 to $40 \mathrm{mg} /$ litre.

Errors in dye calibration can be caused by (a) differences in the 'strength' of the dye used in the factory calibration and in the procedure, and (b) by variation of the cardiogreen concentration in the injectate caused by dilution errors. A rapid and simple check can be performed at the end of the study using $3 \mathrm{ml}$ of the patient's blood and $50 \mu 1$ of the dye solution used. Such a check yields, as a rule, a small correction factor to be applied to cardiac outputs obtained with a given dye sample. The 'strength' of the dye itself has been found remarkably uniform from batch to batch.

\section{Results}

As a rule, the life of these catheters is limited by the life of the sheath. Factory supplied calibration factors have been found not to vary as long as the catheter is usable. Some of the catheters have been used for as many as 20 cardiac catheterisations.

Clotting has not been a problem with any of these

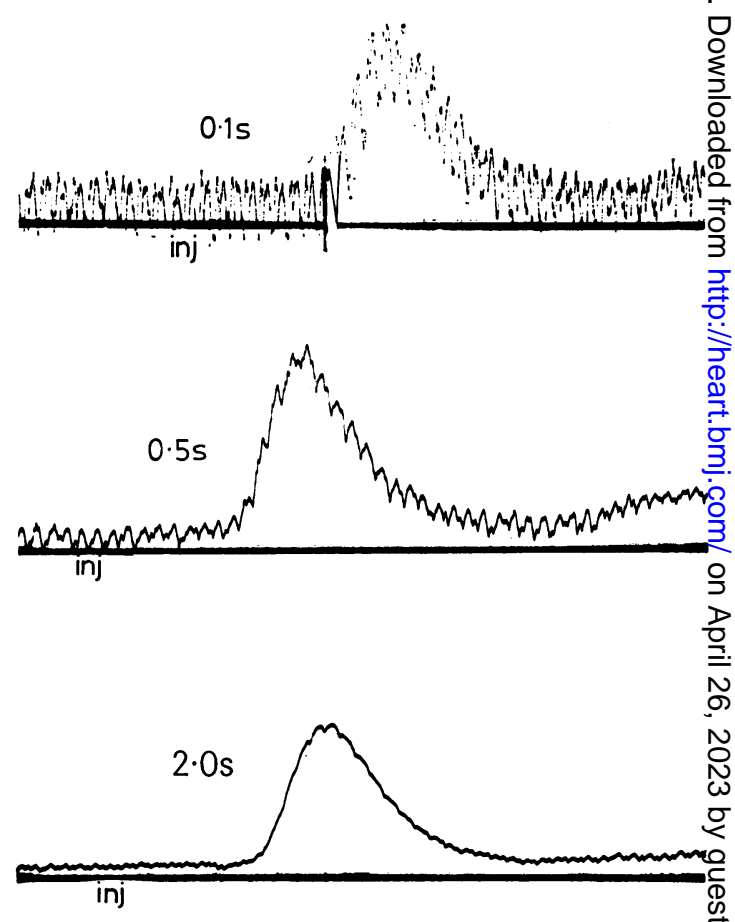

Fig. 4 The effect of altering response time is illustrated by these dye curves which were done in rapid succession in the same patient. Response time is controlled by the electronics rather than being dependent on dead space volume and the speed of withdrawal of blood, as is the case in the usual dye dilution technique. 
catheters. Our patients are routinely heparinised with 1000 units heparin $/ \mathrm{kg}$ before the introduction of arterial catheters. We have not noticed any deposition of fibrin of sufficient magnitude to alter the oximetry measurements or to be detectable visually.

Fig. 3 shows a typical tracing of a pullback in a patient with a ventricular septal defect. Continuous arterial oxygen saturation readings were obtained upon withdrawal from the right pulmonary artery to the right atrium in a patient with a small left-toright shunt.

Fig. 4 shows a set of typical indicator dilution curves in a patient with no shunt. The effect of varying the response time is obvious. For dye curves where only the cardiac output is of interest the $2 \cdot 0$ second response time is best.

\section{Discussion}

Since the initial introduction of the fibreoptic techniques in 1962, acceptance of the instrument has been slow. This has been caused in part by the spurious readings obtained when the tip of the catheter is in close proximity to or in actual contact with cardiovascular endothelium. Another problem has been the expense of the basic instrument and of the catheters. It was found that glass bunales were subiect to breakage and were often unusable after as few as three or four studies.

The present instrument seems to be vastly superior to earlier models. It is equally rapidly responding and is particularly useful for indicator dye dilution techniques. It was found to be capable of detecting small left-to-right shunts and in some instances capable of localising the ventricular septal defects in the outflow portion of the ventricle, clearly indicating the difference in location of the shunt as opposed to a muscular defect.

The instrument is particularly useful for dye dilution techniques since one does not need to withdraw blood through a densitometer. Withdrawal of blood through a densitometer means that one must take care to maintain sterility and to avoid the introduction of air bubbles into the patient. For larger size patients the blood is often discarded but this is obviously impractical for small infants and children. In addition, the response time of the densitometer depends directly upon flow rate through the densitometer as well as inversely upon dead space. It is impractical for the dead space to be less than $0.3 \mathrm{ml}$ and it is difficult to achieve flow rates much greater than 30 to $40 \mathrm{ml}$ per second Furthermore, flow rates as low as $15 \mathrm{ml}$ per second. have been shown to alter the haemodynamics of neonates during the withdrawal (Gessner et al., 1965).

The fibreoptic system requires no withdrawal of blood and thus simplifies the problems of sterile technique. It also avoids completely the need for withdrawal and reinfusion with all its incumbent hazards of air embolism. In addition, response time can be controlled by the electronics rather than being dependent upon the dead space or the withdrawal rate. Since there is no necessity to reinfuse blood, the next indicator dilution curve may be run as soon as baseline stability is reached, usually within 30 seconds. In practice, this means that dye curves and cardiac outputs may be obtained at very brief intervals to check upon changing haemodynamics during drug infusion or similar dynamic studies.

\section{References}

Ensin, Y., Jamason, A. G., and Cournand, A. (1964). Intracardiac oximetry in congenital heart disease. Circulation, 29, 499-507.

Frommer, P. L., Ross, J., Jr., Mason, D. T., Gault, J. H., and Braunwald, E. (1965). Clinical applications of an improved, rapidly responding fiberoptic catheter. American fournal of Cardiology, 15, 672-679.

Gamble, W. J., Hugenholtz, P. G., Monroe, R. G., Polanyi, M. L., and Nadas, A. S. (1965). Use of fiberoptics in clinical cardiac catheterisation. I. Intracardiac oximetry. Circulation, 31, 328-343.

Gessner, I. H., Krovetz, L. J., Benson, R. W., Prystowsky, H., Stenger, V., and Eitzman, D. (1965). Hemodynamic adaptations in the newborn infant. Pediatrics, 36, 752-762.

Hugenholtz, P. G., Gamble, W. J., Monroe, R. G., and Polanyi, M. L. (1965). The use of fiberoptics in clinical cardiac catheterisation. II. In vivo dye dilution curves. Circulation, 31, 344-355.

Polanyi, M. L. (1974). Fiberoptics in cardiac catheterisation. In Dye Curves, pp. 267-283. Ed. by D. A. Bloomfield. University Park Press, Baltimore.

Polanyi, M. L. (1975). Recent development in fibre optics oximetry. In Oxygen Measurements in Biology and Medicine, pp. 369 381. Ed. by J. P. Payne and D. W. Hill. Butterworths, London and Boston.

Requests for reprints to Dr L. Jerome Krovetz, Department of Pediatrics, Box 386, University of Virginia Hospital, Charlottesville, Virginia 22901, USA. 